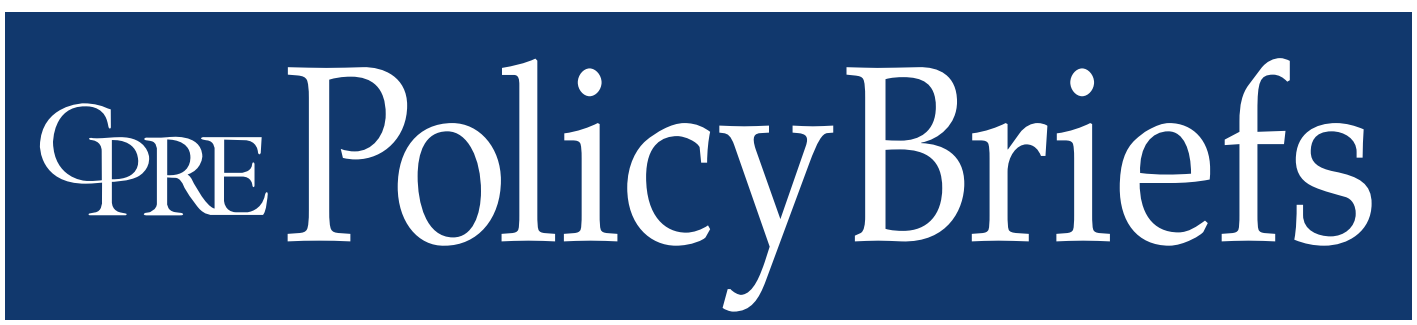

Reporting on Issues and Research in Education Policy and Finance

\section{The Role of Learning Progressions in Standards-Based Education Reform}

\section{Frederic A. Mosher}

The new Common Core State Standards (CCSS), the National Research Council (NRC) framework for common science standards, the federal criteria for supporting Race to the Top Assessment Program state consortia, and the plans of the two supported assessment consortia all in one way or another call for defining the K-12 path students should be on if they are going to meet the standards of knowledge and skill in core subjects that would indicate readiness to succeed in college or other post-secondary career pursuits. By assigning standards specifically to grade levels all of these documents recognize that students' learning develops over time and that instruction should be arranged to ensure that the necessary earlier experiences and learning in fact happen in an appropriate order so that later learning can build on them. Standards tend to emphasize what educators should be delivering to students and asking them to do. But clearly, the relevant precursors not only have to be made available to students, they actually have to be learned, if learning is to progress as desired. When they are not learned, or if the pace of learning for some students is too slow to reach the standards' targets by the normal age of graduation, in a standards-based system, educators will have to do more than just delivering the content.

If we expect substantially all children to meet standards, schools and teachers will have to take responsibility for monitoring students' progress and intervening on a timely basis when needed, so that students know when and how they are falling off the

\section{"What students can learn at any particular grade level} depends upon what they have learned before. Ideally then, each standard in this document might have been phrased in the form, 'Students who already know... should next come to learn...' But at present this approach is unrealistic - not least because existing education research cannot specify all such learning pathways. Of necessity therefore, grade placements for specific topics have been made on the basis of state and international comparisons and the collective experience and collective professional judgment of educators, researchers, and mathematicians. One promise of common state standards is that over time they will allow research on learning progressions to inform and improve the design of standards to a much greater extent than is possible today." (Common Core State Standards for Mathematics, 2010, p.5)

common track and can more productively take their own responsibility for trying to do better. In order for students to get back on track, they also need feedback and supporting experiences that are responsive to the particular difficulties they are having.

For many teachers this represents a major shift in responsibility from a historically more prevalent approach that focuses on simply presenting the subject and accepting that students succeed or fail in learning it according to their ability and effort.

The difference is recognition and acceptance of the teacher's obligation to seek evidence of whether students are in fact understanding and making appropriate
September 2011 RB-52

Graduate School of Education

University of Pennsylvania

This Policy Brief was derived from two extensive research reports:

Corcoran, T., Mosher, F. A., \& Rogat, A. (2009).

Learning Progressions

in Science: An

Evidence-based Approach to Reform

(Research Report \#RR-63).

Daro, P., Mosher, F., \&

Corcoran, T. (2011).

Learning trajectories in mathematics: $A$ foundation for standards, curriculum, assessment, and instruction

(Research Report \#68).

Visit www.ccii-cpre.org to download free copies

\section{Consortium for Policy Research in Education}

University

of Pennsylvania

Teachers College Columbia University

Harvard University

Stanford University

University of Michigan

University of WisconsinMadison

Northwestern University 
progress, and to act on that evidence as needed to try to help them catch up or keep moving ahead. CPRE's Center on Continuous Instructional Improvement (CCII), along with other observers, would label these processes of gathering evidence of progress and problems - and acting

All data presented, statements made, and views expressed in this report are the responsibility of the author and do not necessarily reflect the views of the Consortium for Policy Research in Education, its institutional partners, or the funders of this study_Pearson Education and the Hewlett Foundation. This brief has been internally and externally reviewed to meet CPRE's quality assurance standards. Special thanks to Brad Findell, independent consultant supporting implementation of the Common Core State Standards, for his thoughtful review and enormously helpful feedback. on that evidence to support students' progress-as "formative assessment" and "adaptive instruction." The two terms have essentially the same meaning: the former emphasizes a focus on gathering evidence of students' progress or problems, but implies a formative response; the latter emphasizes the adaptive or formative response, but it carries the implication that the response is based on evidence of where the students are and where they need to go.

The fundamental idea here is that students, if they are to meet college-and careerready standards by sometime toward the end of their high school careers, will need to be "on track" over the earlier years, in the sense that they will be building over time the knowledge and skills that will get them to the levels the standards require in later years. And their teachers should understand this path that all students are supposed to be on, how to tell whether and where they are on it, and what to do to help them move ahead.

This raises two big issues for teachers. One has to do with understanding this path or track that students should be on, and being able to recognize important waypoints along it. The other has to do with instructional/pedagogical questions - what does a teacher do to help a student get back on track or catch up if she or he recognizes that the student is somehow off track, behind, or experiencing problems? Knowing the formerwhere the student is - doesn't necessarily reveal the answer to the second question of what to do about it.

\section{Learning Progressions Proposed as a Tool for Supporting Adaptive Instruction}

The concept of "learning progressions" has begun to show up in discussions of education policy and research as a potential answer to the question of how to specify what being "on track" might mean. A number of recent NRC reports on science education highlight the concept (National Research Council, 2001; National Research Council, 2007). The National Science Founda- tion (NSF) is funding quite a bit of research and development on progressions in science and mathematics. Mathematics education researchers tend to use the term "learning trajectories," or "hypothetical learning trajectories," for an essentially equivalent concept. Some national education systems, and some of the Australian states, use the term in describing the levels of learning in their common curricula. As we have noted above, the idea informed the development of the Common Core Standards and turns up as well in the language of the two Common Core state assessment consortia.

In the past three years, with support from Pearson Education and the William and Flora Hewlett Foundation, CCII organized two working groups of scholars and education researchers to review the concepts of learning progressions and learning trajectories as they are being applied in science and mathematics education; their purpose was to try to clarify what they are and what is known about them, and to assess their potential usefulness for informing the development of better standards, curricula, and assessments. As a result of these deliberations, CCII produced two reports, one for science and one for mathematics (Corcoran, Mosher, \& Rogat, 2009; Daro, Mosher, \& Corcoran, 2011). This policy brief reviews their conclusions and the implications of their findings for policy and for future research and development.

\section{What are Learning Progressions?}

At one level, the idea of progressions is simple and obvious. Kids learn. They start out by knowing and being able to do little, and over time they know and can do more, lots more. Their thinking becomes more and more sophisticated. Correspondingly, most curricula are based on some rationale, or choice of scope and sequence, considered appropriate for determining the order in which topics within a subject should be taught over time. But our review of the work on progressions and trajectories found that their serious proponents believe that they are doing something more than traditional curriculum development. Traditional curriculum is based primarily on the logic of the discipline or school subject, the practical wisdom and typical approaches of teachers, and sometimes on the convictions of one side or another in the various philosophical debates about curriculum. Curriculum developers pay attention to what, when, and how concepts and skills should be taught; while there are notable exceptions, they often pay less attention to 
whether and how they get learned when their scope and sequence is implemented.

Proponents of progressions and trajectories argue that their work differs from this traditional approach to curriculum development because it is grounded in empirically tested and testable hypotheses about the ways children's thinking actually develops in interaction with experience and instruction. They focus not only on what the teachers and curriculum are trying to teach - they also try to look closely at what the students are actually attending to and learning, and at the ways their thinking is becoming organized in their minds (and, to be sure, at how that varies with differences in the ways teachers, textbooks, and curriculum are trying to teach them). Ideally, and in some of the examples we saw, they attempt to improve these outcomes by redesigning the experiences provided for children. They proceed in an iterative, experimental fashion until they believe they have found an efficient sequence. The result is a description of an empirically tested pathway that can be called a learning progression (or as we suggest below, a "teaching and learning progression"). (See Heritage, 2008 for a broader review of the construct of learning progression and definitions of it.) [To be fair, there certainly have been curriculum development efforts that have taken a similar iterative approach to their work, testing the results of their designs and revising them accordingly. And, while they may not have used the language of progressions, some have paid attention to research on children's thinking and to assessing the results of their designs in terms of that research. What the new emphasis on progressions brings to the table is an even more explicit emphasis on the ways students' thinking becomes more sophisticated over time in terms of interactions between their growing understanding of content in science and mathematics and their ability to use that understanding in reasoning and solving problems. Really the contrast is with curricula that take a simple focus on facts and specific skills rather than with more recent and ambitious curriculum development work.]

Some of the discussion of progressions seems to imply that they have a kind of developmental or maturational character - that there are characteristic steps or levels that children's thinking tends to go through somewhat independently of experience, or that experience may change the timing or rate of growth, but not the order of these steps. However, while the researchers studying progressions and trajectories accept that children may well have some innate dispositions to attend to particular quantitative or causal aspects of their experience of the world during early development - dispositions that may provide a starting point for the development of mathematical and scientific understanding - they make it clear that neither scientific understanding nor knowledge of mathematics can develop very far without effective instruction.

Generally, empirical work on progressions starts with a societally defined learning goalsuch as understanding counting, or operations with numbers, or the particle, or the atomic-molecular, models of matter, carbon/energy cycles, or genetics and evolution - and then, rather than simply "back-mapping" logically to necessary prior knowledge, it tries to identify the precursor ideas about these domains that children are likely to bring with them to school. These early ideas are the ones most likely to have developmental roots, but certainly by the time of school or preschool they also are heavily influenced by a child's particular family and by the "folk theories" implicit in their language and culture. Progressions researchers then try to follow how children modify their early ideas, or replace them, in response to instruction and experience, both in and outside of school. They use clinical interviews, close observations in experimental and classroom settings - sometimes following children or cohorts of children longitudinally, sometimes looking at cross-sectional data from observations or assessments of cohorts at different ages or grades. Often the observational work is closely coupled with design studies, in which the researchers/developers form and test hypotheses about the kinds of curricular and pedagogical interventions that might improve the chances of moving children's thinking in the desired direction.

\section{Teaching Progressions as Well}

In fact, the most careful and nuanced definitions of progressions all frame them as hypotheses about interactions between changes in distinguishable levels of students' thinking and skills or practices as they move, or fail to move, toward the goals of instruction, and an ordered set of experiences, tasks, and instructional interventions that are intended to encourage the students' thinking to grow from level to level toward the goal. Thus, there are really two progressions involved here: a learning progression, and a teaching progression. The two are analytically distinguishable, but they are deeply inter- 
twined practically. Beyond the earliest years, and certainly by pre-school ages, they really should be called "teaching and learning progressions," or "instructional progressions." It also needs to be stressed that both kinds of progressions are hypothetical - that is, they are expectations about how learning will develop and what experiences will encourage it, based on the best available empirical evidence, subject to further testing and refinement.

The work on learning progressions ranges in grain size - from one day's lesson to the entire Pre-K-12 grade span. No matter what the grain size, the teaching and learning described in a progression will often be affected by teaching and learning of other concepts and skills, both within the same subject and across subjects, which also may be described as progressions. For instance, scientific understanding is substantially affected by the mathematics available to students as they learn particular science concepts. The development of students' literacy skills certainly constrains how far they can go in understanding what they read, and how they write, about science. And the depth of students' understanding of a particular science concept and their ability to use it will be affected by where they stand in the development of their understanding of scientific practices - practices such as increasing sophistication in arguing and reasoning from evidence, understanding the nature and purpose of models and modeling, and so on.

A fully adequate picture would look more like a complex map - a construct map or a network of conceptual nodes and contingent connections and interactions - than like a simple linear path or stairway. And no one really thinks there is just one developmentally determined "best" pathway. But many do think that it is possible to identify paths that are particularly productive and more consistent with the ways children and students are likely to attend to and benefit from instruction (Sarama \& Clements, 2009, pp.23-24).

Most of the empirical work on progressions tends to focus on the development of particular concepts - often "big" or "core" ideas in the disciplines to be sure - but over short ranges of instruction, often only one or a few grades, and sometimes just over a smaller sequence of lessons; they tend to treat the interactions with other related progressions - in mathematics and literacy with respect to science, for instance - as somehow "other things being equal" for the purpose of focusing on the progression for the par- ticular focal concept. This isolation can be practically helpful to teachers and lesson designers, since it is hard for them to attend to everything at once. And the people doing this work often find reassuring evidence that although students in any given class may vary quite widely in where they stand on a particular defined progression (of course a central problem that teachers have to deal with), the number of distinct progressions they will face in a particular classroom may be finite, small, and in principle manageable.

Some examples of good work of this sort are: Robbie Case and colleagues (1996), or Herbert Ginsburg (1983), on counting and number; or Douglas Clements and Julie Sarama on counting (2009, pp.19-41), number operations (2009, pp.59-80), and on conceptions of shape and precursors of geometry (2009, pp.123-162); Jeffrey Barrett and colleagues (2009) and Barrett and Michael Battista (2011, in press) on linear measurement; Jere Confrey and colleagues on equipartitioning and rational number (Confrey et al., 2009); Marge Petit and colleagues (2010) on fractions and multiplicative and proportional reasoning; Carol Smith, Marianne Wiser, and colleagues (2004), and Joseph Krajcik (Stevens, Delgado, \& Krajcik, 2010) on the development of the atomic-molecular model of matter (which taken together runs across the elementary and middle school grades); Andy Anderson on carbon cycles in socio-ecological systems (Mohan, Chen, \& Anderson, 2009); and Brian Reiser (Schwarz et al., 2009), and Richard Lehrer and Leona Schauble (2000), on conceptions of models and modeling.

All of them find that they can identify a sequence of distinguishable levels or constellations of understanding and skill that are stable for a student for at least some period of time, and represent steps advancing along a path between what the students bring with them into school and what they should end up with after adequate instruction. Most would agree that when, and while, the levels are stable for students they tend to respond (in solving problems for instance) characteristically as the description of the level would predict. However, students may fall back to earlier levels in the face of more difficult problems or under the pressure of stress or time. And as they move to the next level there usually are periods of greater instability as elements of the earlier or later level are used. The component elements of the new level may be learned in different orders during the transition. 
For space reasons we can provide only two examples of what these descriptions of levels of children's thinking on particular progressions can look like. The first shows a portion of a learning trajectory describing the growth of children's understanding of linear measurement, based on the work of Barrett, et al. (2011, in press) and Sarama and Clements (2009) (see sidebar below). It is an example of a single-progress dimension over a relatively brief age span of growth. The second is excerpted from the work of an ongoing Rapid Response Research Project (RAPID) organized by CPRE and supported by the NSF intended to provide examples for how learning progressions might instantiate and inform the new framework for common science standards that has been developed by a NRC committee (see sidebar on p.6). One of their examples takes up the standards framework's focus on what students should learn about the structure and properties of matter as part of the physical science section of the framework.

Modified Illustration of a portion of a learning trajectory describing the growth of children's understanding of linear measurement (the age attributions are approximate, within a range, and they are not directly referenced to the Common Core State Standards).

\begin{tabular}{|c|c|c|}
\hline Trajectory Level & Conceptual Structures & Example of Instructional Task \\
\hline $\begin{array}{l}\text { Age 6: End-to-End Length } \\
\text { Measurer (EE): Lays units } \\
\text { end-to-end. May not } \\
\text { recognize the need for } \\
\text { equal-length units. Needs } \\
\text { a complete set of units to } \\
\text { span a long object. }\end{array}$ & $\begin{array}{l}\text { Expects that lengths can be } \\
\text { composed as repetitions of } \\
\text { shorter lengths. This initially } \\
\text { only applies to small numbers } \\
\text { of units. The scheme is enhanced } \\
\text { by the growing conception of } \\
\text { length measuring as sweeping } \\
\text { through large units coordinated } \\
\text { with composing a length with } \\
\text { parts (unit sticks). }\end{array}$ & $\begin{array}{l}\text { How long is the black strip, compared to one of the blue strips? } \\
\text { Can you find out without moving any more blue strips? }\end{array}$ \\
\hline
\end{tabular}

Age 7: Length Unit Relater and Repeater (URR):Measures by repeated use of a unit (initially may be imprecise as with broken ruler tasks). Relates size and number of units explicitly, but may use units of varying lengths. Can add lengths to obtain the length of a whole. Iterates a single unit to measure. Uses rulers with minimal guidance.
Action schemes include the ability to iterate a mental unit along an object. Cardinal values are connected to space units for small quantities but weaker beyond these. With the support of a perceptual context, scheme can predict that fewer larger units will be required.
If the black strip is reported to be 4 units long by a struggling student, have them find the length of the blue and grey strips. If the student reports 3 and 2 for these measures, ask them to draw a 1 unit long segment. Or, ask them how many 2 unit grey strips would make up a 3 unit blue strip. This should prompt them to re-measure and build up the grey as 1 unit, the blue as 2 units, and the black as 3 units.

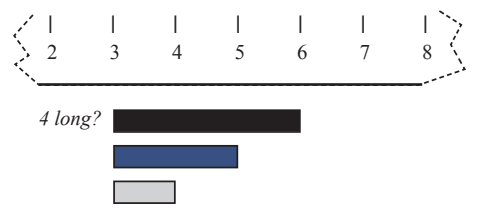

Age 8: Consistent Length Measurer (CLM) Finds length on a bent path as the sum of its parts. Measures consistently, knowing need for identical units, partitions of unit, zero point on rulers, and accumulation of distance. May coordinate units and subunits.
Scheme includes the ability simultaneously to imagine an object's length as a total extent and a composition of units. Only allows equal-length units. Can measure from starting points other than zero on a ruler. Units themselves can be partitioned to increase precision.
Draw 4 different paths that are shorter than 5 and one half inch and longer than 5 and one quarter inch. Put the paths in order, and describe the length of each one in inches.

Sources: Barrett, J., Clements, D., Sarama, J., Cullen, C., McCool, J., Witkowski, C., \& Klanderman, D. (in press). Evaluating and Improving a Learning Trajectory for Linear Measurement in Elementary Grades 2 and 3: A Longitudinal Study. Mathematical Thinking and Learning.

Sarama, J., \& Clements, D. H. (2009). Early childhood mathematics education research: Learning trajectories for young children. New York: Routledge. 
Based on work by Smith and Wiser for the early grades, and Krajcik and colleagues for the later, the hypothetical progression traces the ways students are likely to think about stuff or material kind, and later "matter," from early "macroscopic compositional models" (things are made of stuff that seems to have characteristic properties) through "microscopic compositional models" (still just solids and liquids but the stuff can be divided indefinitely into smaller and smaller pieces that retain their character), to a "particle model" that considers matter to be made

Structure \& Properties of Matter:

What is matter made of and how does its composition relate to its properties?

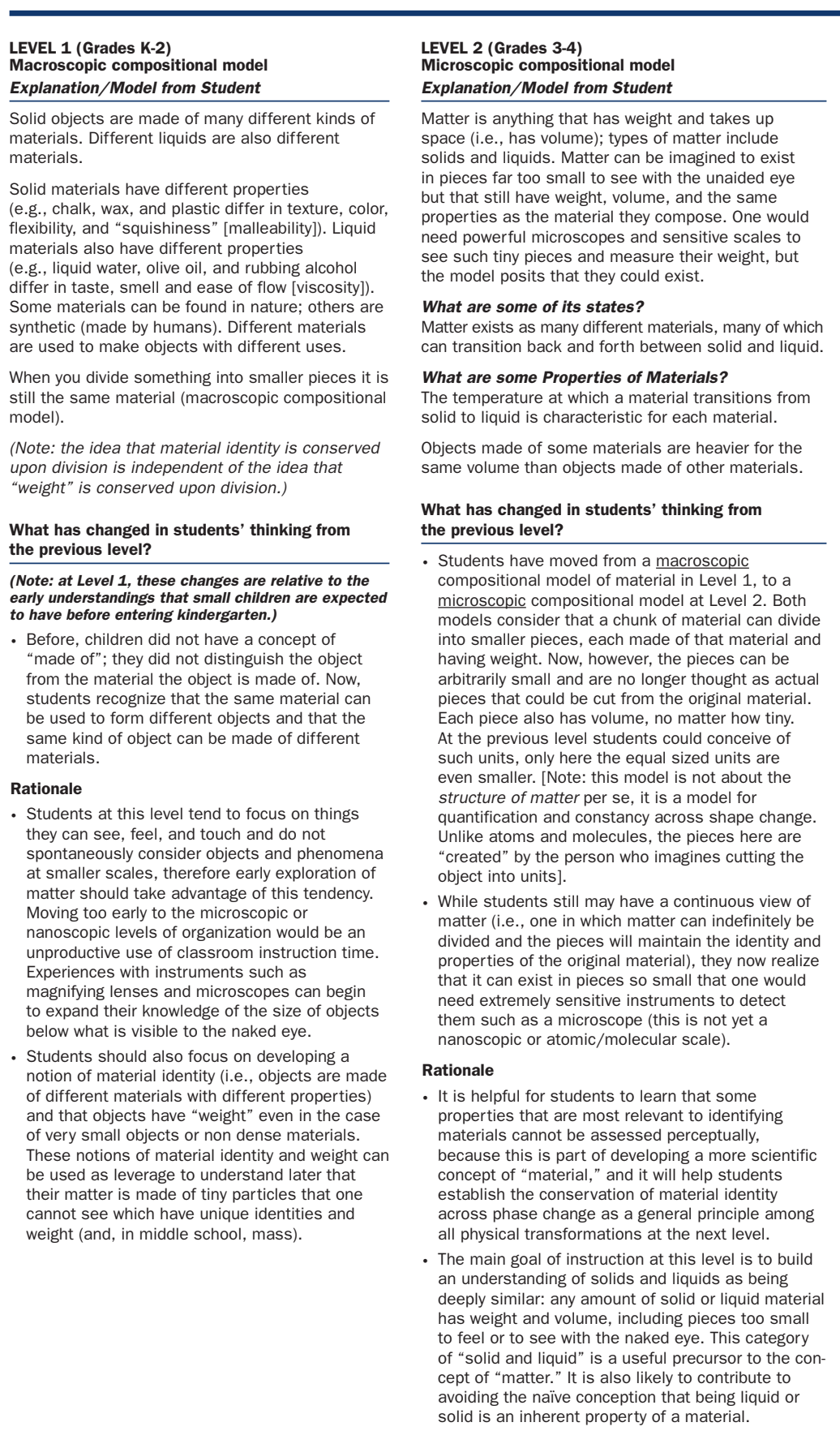

\section{LEVEL 3 (Grades 5-6) \\ Explanation/Model from Student}

Solid, liquids, and gases consist of extremely tiny particles that cannot be seen with the unaided, eye, nor even with a light microscope. There is empty space between particles. Particles in gases are much further apart than particles in solids and liquids. Since particles are extremely small, and in gases they are far apart, that is why gases are invisible. Each particle weighs a tiny amount, so gases have weight. Since gases have weight and occupy space, they are matter, like solids and liquids. Gas particles move in straight lines until they hit other particles or the walls of the container. For each particular substance, particles in the liquid phase move more slowly than particles in the gas phase for that same substance, and particles in the solid phase move still more slowly (except during a phase change, such as boiling or melting). Particles in a solid move back and forth around fixed positions without colliding with each other.

Different substances are made of different "particles".

What causes materials to expand or contract? When a solid, liquid, or gas is heated, the average speed of the particles increases and there is a slight increase in the average distance between the particles. This change in speed and spacing upon heating results in an increase in volume. Upon cooling, materials contract. Contraction is possible because there is empty space between particles, so there is room to compress into a smaller volume. As learned in Level 2 , with enough heating, a phase change will occur.

\section{What has changed in students' thinking from} the previous level?

- Students move from a microscopic compositional model to a particle model of matter (reflecting a major shift in thinking).

In the previous grade band, they could envision

materials as made of arbitrarily small pieces but materials as made of arbitrarily small pieces but
those pieces did not pre-exist in materials, they were created by physically or mentally dividing a sample of material. The particulate model prepares students for the atomic-molecular model presented in Level 4 (Grades 7-8).

\section{Rationale}

- The particle model is a very important intermediate model of matter. It is not scientifically complete, since it does not include a notion of atoms and molecules, but it is critical for getting students to think about matter at very small scales and to account for gases, thermal expansion and contraction, and density. However this model does not account well for chemical reactions and therefore its applications are limited to physical properties of substances.

Source: CPRE's Rapid Response Research Project (RAPID), “Developing Hypothetical Learning Progressions in Support of the Implementation of New Science Standards," funded by the National Science Foundation (award no. DRL-1051144). ${ }^{1}$

${ }^{1}$ CPRE's RAPID project is a work in progress as is the content provided in the modified table above. CPRE's RAPID project is led by Aaron Rogat (PI). Members of the project team who collaborated on the physical sciences hypothetical learning progression include: Jacob Foster, Fred Goldberg, Joseph Krajcik, Marianne Wiser, Shawn Stevens. 
up of discrete equal size pieces with characteristic properties - too small to be seen even with microscopes and always in motion - and that can accommodate/explain gases as well as solids and liquids, and then on to atomic and molecular, and then sub-atomic models. Here we show just the introductory headings to the much more elaborate tables that lay out the learning performances and instructional tasks that both reveal where students are in the progressions and promote their movement through them. The headings describe what is changing in students' thinking as they move through the first three of the five identified models that are characteristic of the levels of progress in students' conceptions of matter. What we show here are excerpts from the somewhat more elaborate material in the headings in the full table, but we hope they are enough to give a sense of how the progression works. Because this work has been tied to the NRC committee's standards framework, it is organized in terms of grade-level or grade-band expectations, but in progressions terms the important points have to do with the order in which the models develop.

This progression of models of the structure of matter represents an example of what below we call a "progress variable" - that is, a characterization of one substantive dimension along which students' concepts develop. In the RAPID project this progress variable is paralleled by another dealing with students' thinking about how matter can change or be transformed, as in phase or state changes, and "physical" and chemical transformations. In addition, there are parallel dimensions of progress - dealt with explicitly or implied - that interact with these dimensions and involve the ways students deal with quantifying the relations and measurements involved in their observations of material phenomena, and the levels of sophistication in which they reason and argue about what they are observing.

This excerpt from the RAPID project's progression presents learning as a moving target over a longer period of time than the first example. It is disciplined by close observation of what students say and seem to think, but it also represents hypotheses about what might advance their understanding based on an awareness of where they would need to go if they are to grasp the world in anything like the ways that modern scientists do (and what it would take to help them see that those ways are sensible and justified). Hypotheses about learning of this sort need to be tested and refined in practice, again and again.

In principle, at least, we would argue that these hypothetical progressions provide a useful way of thinking about what "being on track to meeting standards" actually might mean. However, our review of work in the field also suggests that this work is in an early stage, and it is incomplete in terms of well-supported understanding of how students' knowledge and skill develop, with appropriate instruction, across the whole K-12 span. Nevertheless, we think that combining empirical understanding of progressions, where it exists, with the best available thinking about curriculum design aligned with the Common Core Standards, could define a kind of ordered "spine" of fairly well defined levels of thinking and understanding that could serve as reference points for assessments, and such assessments might justifiably be said to track where students are on their way to meeting the core standards.

\section{Tensions with, and Potential Support for, Standards}

As they are currently conceived, the Common Core State Standards consist of grade-level prescriptions for what all students should understand and be able to do by the end of each grade, in order for them to remain on track to being college- and career-ready by the end of high school. It is important to recognize that there is a fundamental tension, or difference in perspective, between characterizing points on this path the way current standards do - as the particular knowledge and skill that students ought to have acquired by the end of each grade, or at some point in high school, depending on their courses - and the progressions approach that describes the full array of significant steps that students are likely to go through along the way, if they eventually succeed in meeting the goals of instruction. The progressions orientation encourages determining where students actually are on that path rather than simply noting whether they have reached the level the standards expect them to at the end of each grade, grade band, or course.

Of course, these perspectives are not necessarily incompatible. Clearly, if you can identify ordered levels, you can turn any of them into standards or goals that ought to be reached by a particular time. But focusing on what children ought to be able to do by now, as opposed to what they are in fact now doing makes a difference for both practice and policy. Treating the levels in standards terms as requirements, for instance, tends to lead to a pass/fail view of assessment with limited attention to evidence about 
where a student who falls short of the required performance might nevertheless be. A progressions approach, in contrast, might be more likely to seek evidence that locates a student's performance along the relevant array of levels leading up to the goals of instruction. That kind of evidence offers the possi-

"Focusing on what children

ought to be able to do by now, as opposed to what they are in fact now doing makes a difference for both practice and policy. Treating the levels in standards terms as requirements, for instance, tends to lead to a pass/fail view of assessment with limited attention to evidence about where a student who falls short of the required performance might nevertheless be. A progressions approach, in contrast, might be more likely to seek evidence that locates a student's performance along the relevant array of levels leading up to the goals of instruction.

That kind of evidence offers the possibility of informing teaching that is adjusted much more precisely to what may be required to help the student continue to progress than can be supported by the simple observation that the student has not met the standard." quired for students to develop those ideas by graduation. These steps derived from the logic of the disciplines are of course usually modified in the standards-setting process by factoring in the practical experience of teachers and curriculum developers, which does introduce some real world discipline to the process, but it still can lack grounding in evidence about what most children are actually able to do - in some cases overestimating their likely understanding but also sometimes underestimating it. A progressions approach on the other hand ought to start with, or to be deeply rooted in, empirical observations of students' thinking, as it develops during the course of instruction. In principle, that grounding could support the development of progression-based standards that are more realistic, attainable, and motivating both to students and teachers.

So, a progressions approach ought to provide a basis for developing more precise evidence of where students are on their path to meeting standards and for helping teachers understand the implications of that evidence in ways that would help them to adapt their instruction to their students' particular needs. Over time, it ought also to provide evidence to the education system on what is reasonable to expect from most students and what kinds of resources and instruction would realistically be needed to help most of them meet higher expectations. This evidence would inform the kinds of trade-offs between what ideally is possible with a maximum effort and what is reasonable in the real world that standards setting always involves. Nevertheless we find that making this shift to focusing on empirical descriptions of the development of students' thinking in the context of instruction is hard. It is hard for policymakers concerned with standards and accountability. It is hard for educators. And it is hard even for proponents of the progressions concept, as we suggest in what follows.

\section{Persistence of a Summative Bias, Abetted by Current Limitations of Our Formative/Adaptive Knowledge}

Some of the reason for this difficulty can be found by taking a closer look at the ways progressions are being defined. The members of our panel on learning progressions in science came to an agreement on a working definition of progressions and a list of their key components and common attributes. We present the definition and a substantial part of the list of attributes in Table 1. We recognize that this definition is unwieldy, to say the least, but we think that captures the fact that this is work in progress at an early stage, with many moving parts that have not yet jelled into a more formal statement. As indicated in the report, the definition is substantially derived from the definitions provided by Smith and colleagues in their NRC report (Smith, Wiser, Anderson, \& Krajcik, 2006) and the NRC report on K-12 science learning (National Research Council, 2007). It recognizes that the ultimate targets of the hypothesized progressions are based on goals determined by society and the disciplines relevant to the school subjects, informed 
by research and expert judgment, not targets that students themselves would initially be aware of, but it attempts to focus on the actual development of students' thinking as, or if, it moves toward those goals, and on hypothesizing what might encourage that movement. However, because the definition and the associated list of attributes use the language of "achievement levels" and "learning performances" it seems to be all too easy for policymakers and even proponents of progressions to shift into a more conventional standards orientation, in which learning performances become what students are expected to be able to do to meet standards by a particular time, and assessments become the test of whether they do in fact meet those expectations.

This subtle shift in orientation reflects the persistence of a summative/grading approach to assessment - and instruction - in our schools, one which focuses on whether or not students meet expectations rather than identifying where they are in order to figure out what might help them to move forward. ${ }^{1 \text { (see page 10) }}$

Beyond that, there also is the problem that the empirical work necessary to develop and justify hypotheses about the specific levels of thinking

Table 1. Working Definition of LPs in Science (Corcoran, Mosher, Rogat, 2009, p.37)

Learning progressions are hypothesized descriptions of the successively more sophisticated ways student thinking about an important domain of knowledge or practice develops as children learn about and investigate that domain over an appropriate span of time. They must contain at least the following elements:

1 Target performances or learning goals which are the end points of a learning progression and are defined by societal expectations, analysis of the discipline, and/or requirements for entry into the next level of education;

2 Progress variables which are the dimensions of understanding, application, and practice that are being developed and tracked over time. These may be core concepts in the discipline or practices central to scientific work;

3 Levels of achievement that are intermediate steps in the developmental pathway(s) traced by a learning progression. These levels may reflect levels of integration (i.e. of related concepts and/or practices) or common stages that characterize the development of student thinking. There also may be intermediate steps of this sort that are non- canonical but are stepping stones to canonical ideas;

4 Learning performances which are the kinds of tasks students at a particular level of achievement would be capable of performing. They provide specifications for the development of assessments by which students would demonstrate their knowledge and understanding; and,

5 Assessments, which are the specific measures used to track student development along the hypothesized progression. Learning progressions include an approach to assessment, as assessments are integral to their development, validation, and use.

In addition, the panelists believe that learning progressions have some other common characteristics:

1 They are based on research in science education and cognitive psychology, etc.;

2 They are focused on foundational and generative disciplinary knowledge and practices;

3 They have internal conceptual coherence along several dimensions. The progress variables capture important dimensions of scientific understanding and practice and the achievement levels represent the successively more sophisticated levels of understanding and practice characterizing the development of student thinking over time. A progression may describe progress on a single progress variable or a cluster of related (and not just parallel) progress variables. Some progressions may provide an underlying cognitive account that leads to an expectation of the same or comparable achievement levels across the variables - a particular kind of "coherence." Such expectations of course require empirical verification;

4 They can be empirically tested;

5 They are not developmentally inevitable, but they may be developmentally constrained;

6 They are crucially dependent on the instructional practices provided for the students whose development is studied in the processes of development and validation. Targeted instruction and curriculum may be required for students to progress along a progression; and,

7 There may be multiple possible paths and progress is not necessarily linear. It may be more like ecological succession. A learning progression proposes and clarifies one (or more) possible paths and does not represent a complete list of all possible paths. At any given time, an individual may display thinking/practices characteristic of different points on the path, due to features of both the assessment context and the individual's cognition. 
and skill students' understanding will progress through on the way to meeting the ultimate goals of schooling is still quite limited. Absent that work, it is quite natural to fall back on making rational guesses about what order of instructional topics and content ought to lead students to reach the ultimate goals of instruction and to translate those guesses into ordered standards and performance expectations. That is hardly a foolish strategy, and if it is done openly and explicitly, and draws heavily on practitioners' experience,

"It is much easier to

assert what students are

supposed to know than

to find out exactly what

they do know, and it is

even harder to know

what to do to get from

one to the other.

Progressions must

provide an empirical

picture of students'

actual learning at a

grain size that can

inform teachers'

thinking about next

steps if they are to

support better

instruction and

student success." it is a quite reasonable way to approach developing early approximations of hypothetical progressions. But the progressions discussion should not stop there. It is much easier to assert what students are supposed to know than to find out exactly what they do know, and it is even harder to know what to do to get from one to the other. Progressions must provide an empirical picture of students' actual learning at a grain size that can inform teachers' thinking about next steps if they are to support better instruction and student success.

\section{Caution about Over-Promising the Benefits of Progressions- the Role of Progress Variables and Practices}

Progressions are sometimes touted as tools that will help students to acquire higher level or deeper thinking skills - capabilities that are beyond or different from just higher levels of content knowledge in school subjects (see for instance www.deeptutor.org). We think these are not necessary outcomes of a progressions approach. If they are to be fostered, these outcomes would have to be identified clearly and their development would have to be treated explicitly as the desired outcome of a progression or progressions in their own right. In this regard, perhaps the component of progressions called "progress variables" in Table 1, and the notions of scientific and mathematical "practices" that are widely discussed in the science and mathematics education litera- tures, can encompass much of what might be involved in explicitly identifying and attending to the development of kinds of thinking that go beyond content per se. Let us consider progress variables and practices further.

"Progress variable" is simply a label used to identify the attribute or signfificant component attributes of a learning progression that become more complex or sophisticated over time (Kennedy \& Wilson, 2007; Masters, Adams, \& Wilson, 1990). The idea of progress variables involves a recognition that learning anything significant almost certainly involves growth along multiple interacting paths, some of them within the particular content or subject being singled out to be learned, but some cutting across domains (as we mentioned above, for example, in the kinds of mathematical understanding that are necessary for full understanding of scientific concepts, or the kinds of advancing literacy skills that are necessary for learning both science and mathematics).

"Practices" are a particular class of progress variables. Mathematical and scientific concepts are not normally just learned in the abstract. They are learned as they are being applied and used. "Practices," while not a terribly precise term, refers generally to discipline specific and cross-disciplinary ways of thinking about, using, and even generating disciplinary concepts. "The scientific method" of course is one more familiar label for a set of practices that constitute the ways scientists go about doing their work. More specific examples include developing sophistication in scientific argument,or a com-

\begin{tabular}{|l} 
Science and \\
Engineering Practices \\
(NRC, 2011) \\
$\mathbf{1}$ Asking questions \\
(for science) and \\
defining problems \\
(for engineering) \\
$\mathbf{2}$ Developing and using \\
models \\
$\mathbf{3}$ Planning and carrying \\
out investigations \\
$\mathbf{4}$ Analyzing and \\
interpreting data \\
$\mathbf{5}$ Using mathematics, \\
information and computer \\
technology, and \\
computational thinking \\
$\mathbf{6}$ Constructing explanations \\
(for science) and \\
designing solutions \\
(for engineering) \\
$\mathbf{7}$ Engaging in argument \\
from evidence \\
$\mathbf{8}$ Obtaining, evaluating, \\
and communicating \\
information \\
\end{tabular}
mitment to seeking and using empirical evidence to test hypotheses, or understanding the use and nature of scientific models to explain natural phenomena, or recognizing the role of contextual constraints in the engineering design process, and

\footnotetext{
${ }^{1}$ The summative focus used to be on where students ranked relative to each other, rather than specifically on where they stood with reference to levels of "proficiency" in a subject. In either case the summative emphasis undermines consideration of what would help students move forward, and even now there is a lingering hangover of the relative/ranking interpretations of achievement buried deep in the psychometric methods used to develop standards-referenced assessments of performance.
} 
Mathematical

Practices

(CCSS Mathematics, 2010 pp.6-8)

1 Make sense of problems and persevere in solving them.

2 Reason abstractly and quantitatively.

3 Construct viable arguments arguments and critique the reasoning of others.

4 Model with mathematics.

5 Use appropriate tools strategically.

6 Attend to precision.

7 Look for and make use of structure.

8 Look for and express regularity in repeated reasoning. so on (see sidebar on p. 10). In mathematics there are practices of proof or generalization or, again, modeling and argument, that become more sophisticated over time (see sidebar). Any of these can be identified and considered abstractly as

For instructional purposes, we have suggested it would be helpful to focus attention on more short range and more specific content progressions, or limited content and practices interactions, so that teachers are not overwhelmed by having to take everything into account at once. That suggests foregrounding content over practices, but that can't be the last word. We ought eventually to be able to do better. Curricula based on existing progressions won't necessarily support students in developing more sophisticated practices and thinking. That will require research and development focusing specifically on understanding how practices in fact become more sophisticated - how they progress. There is good work of this sort going on. Probably the most attention so far has been given to argument, to modeling, and to epistemic reasoning (Kuhn, 2005; Schwarz et al., 2010; Lehrer and Schauble, 2000), and that work can model what should happen for other practices. The Common Core standards rightly recognize argument as a practice that cuts across literacy, science, and mathematics, and in prioritizing future research, it will undoubtedly be helpful to identify other practices with such connections.

well students should be expected to reason about the required content is difficult. This seems to us to be a necessary consequence of the fact that learning proceeds along multiple paths at the same time, and while the paths interact, they are not in lockstep. People using a progressions approach probably should not try to make arbitrary guesses about the quality of performances or practices that students who are at a particular level of conceptual understanding should be able to demonstrate. That expectation should grow out of empirical evidence from students who have had instructional exposure to experiences designed to promote growth of understanding of both content knowledge and practices. It will take time to develop that evidence.

In the short run, a kind of guessing will have to be involved in specifying the sorts of performance that can be expected of students who are "at" a particular level of conceptual understanding, but we think that should be based on teachers' practical knowledge and on a clear specification of the kinds of performances students should have been asked to do during classroom experiences that have been derived from hypothesized teaching progressions. It should not simply be derived from applying a check list of practices to each bit of content knowledge to produce a list of expected performances.

\section{Curricula and Assessments}

Curricula specify the order, and often the way, ing and learning progressions represent hypotheses about the kinds of instruction and experiences that should effectively enable students' thinking and skills to develop along a path to reaching goals set for a school subject. In that sense, progressions can provide a framework for developing curricula and specifying how their effectiveness could be tested, but it should also be recognized that progressions, grounded as they should be in evidence and hypotheses about the relationships between teaching and the growth of students' learning, already represent forms of curricula. As we already have noted, given the limited number of content areas that have been covered so far by good progressions research and development, in the near term the many gaps will have to be filled by developers doing the best they can to devise curricula that take into account whatever is known about the growth of students' thinking in the relevant domains and that try to present students with experiences that build in a reasonable and coherent way over time to instructional goals and standards. If close empirical attention is paid to how students' understanding and skill actually develop when they are exposed the elements of a subject should be taught. Teach- 


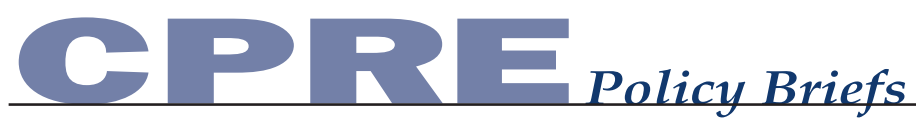

to such curricula, and if the curricula are revised in response to that evidence and tried again in a continuous improvement cycle, the result should be something that will be functionally equivalent to, and perhaps indistinguishable from, the development of progressions in those domains. The key is paying attention to the effects of instruction on the growth of students' understanding, rather than

"If close empirical

attention is paid to how

students' understanding

and skill actually

develop when they are

exposed to such

curricula, and if the

curricula are revised

in response to that

evidence and tried again

in a continuous

improvement cycle,

the result should be

something that will be

functionally equivalent

to, and perhaps

indistinguishable from,

the development of

progressions in those

domains." just trying to figure out a reasonable approach to the order in which instruction should be "delivered." It is our impression that many of the NSF supported "reform" mathematics curricula were developed and subsequently revised along the lines of this recommendation, but the details of the lessons they learned tend not to show up in the literature.

\section{Assessment Design, Issues, and Opportunities}

We think a progressions approach raises three important issues, and several related opportunities, for the design of assessments. These have to do with the three elements of the "assessment triangle" described in the NRC's 2001 Report, Knowing What Students Know (Pellegrino et al., 2001): 1) the cognitive model of students' thinking, understanding, and skills, and how they develop, that defines what we are asking tests to tell us about students; 2) the kinds of observable occasions and behaviors (test items, exercises, performances, etc.) that are designed to provide evidence of students' status in terms of the constructs of the cognitive model; and 3) the statistical and other forms of reasoning that would support the desired inferences about students' status based on the evidence of their observed performances - the NRC report named these "cognition, observation, and interpretation."

\section{Referencing Assessment Results to Cognitive Models}

With respect to cognitive models, the progressions approaches that we have described hypothesize that students' learning can be represented as developing through an ordered series of identifiable levels. To the extent that the hypotheses are true or reasonable approximations of reality, it would make sense to want assessments to report in terms of where students are lo- cated with respect to these levels or nodes of understanding and skill. You would want the assessment to allow you to say, for instance, "this student is at the level of using additive rather than multiplicative strategies in understanding and solving multiplication problems." (Petit in Daro, Mosher, \& Corcoran, 2011) You would consider that to be more useful for guiding instruction and giving the student feedback than being able to say "this student is weaker than many students in mathematical ability," or even "this student is at a basic rather than a proficient level in fourth grade mathematics."

You would want assessments that identify and discriminate among defined levels on progressions, rather than discriminating among students on general dimensions or traits such as mathematical ability or scientific understanding. And, as we have said, you would define being on track to meeting standards in terms of where the students are on the levels of a progression, and whether being that many levels away from the goal means that it is likely that a student could meet the goal in the time the student has available. You would describe students' growth from one time to another in terms of whether they move across levels, and, if so, over how many, during the relevant time period.

\section{Designing Relevant Tasks}

With respect to observations of students' performance that would provide evidence on where they are located in relevant progressions, more work needs to be done on how to derive and design items and exercises in such a way that performance on them would provide this kind of evidence. This is a major weakness of our assessments so far, and it represents an important area for further research [see the Alonzo, Neidorf, \& Anderson chapter in Alonzo and Gotwals (forthcoming) for a discussion of potentially suitable item designs]. One really important issue to be clarified in that research has to do with the question of whether it is possible to devise assessment exercises that will be able to tap more advanced or complex levels of performance fairly without knowing the specific kinds of instructional experiences students have been exposed to. Our position is that it is not really possible to design effective exercises to assess more advanced levels of performance without knowing quite a bit about how students have, or should have, been exposed to the specific content and practices to be assessed. You can write complex items or exercises that seem to 
tap more advanced content and skill, but if students don't succeed on them, you can't be sure whether they lack the knowledge or skill or whether they have acquired them in a different form or context. Also, the question of how to assess a student's ability to transfer, or apply, understanding and skills to a new area or problem requires further thought. We would suggest that such things should not be assessed until students have had instructional experiences designed to expose them to such stretches (or, if they are given such assessments and fail, the default interpretation should be that they have not received adequate instruction - certainly not that they would be incapable of doing it if they did have such instruction). Raising these questions about the relationship between curriculum and assessment certainly calls attention to issues that stem from our education system's traditional deference to local control of curriculum, and instruction and the resulting need for more central authorities to claim that standards and assessments are framed in ways that should not interfere with that control.

\section{Choosing Appropriate Interpretive Models-Should Learning be Seen as Discrete, or Continuous, or Both?}

Turning to ways of interpreting assessment evidence, we would argue that the logic of the progressions approach should lead to giving more serious consideration to statistical/interpretive models that treat levels of performance as being discrete and ordered and that try to report in those terms. If the evidence also leads in that direction, it will raise serious questions about the ways assessment information is now used. In particular, an ordinal, levels-based interpretation of student performance will call into question achievement growth models that assume growth is somehow being measured on an interval scale (so that numerically equal scale score gains for students at the bottom of the performance distribution and students at the middle and the top of the distribution can be considered to be the "same" amount of gain). That assumption has always been questionable at best. By focusing on discrete levels of thinking and performance, progressions research suggests that this assumption may be inappropriate, and that would call into question the validity of "value-added" models for teacher evaluation that assume that student gains are being measured on an interval scale. However, these are issues that will have to be played out in other forums. Here we can only suggest that it will be useful to consider whether it is time to explore the use of statistical models that don't assume that the underlying phenomena are arrayed on (multi-) linear, equal-interval scales or dimensions. $^{2}$

The assessments of the Common Core standards now being designed by the two Race to the Top state assessment consortia (and by two other consortia focused on designing related assessments for special populations) represent a major investment in finding ways to assess important aspects of student performance that have not previously been tested well, or at all, in large scale assessment in the United States. Policymakers and educators should closely scrutinize the results of these efforts as they roll out over the next few years to see if they live up to the rhetorical promises that have been made for what they will accomplish. One very useful source of commentary on these efforts is being provided by the Education Testing Service's Center for K-12 Assessment and Performance Management headed by Pascal Forgione (Center for K-12 Assessment \& Performance Management, Educational Testing Service, n.d.), which has been running a series of working meetings of experts on the technical issues that will be raised in trying to meet these promises. In particular, James Pellegrino has a very useful paper, The Design of an Assessment System for the Race to the Top: A Learning Sciences Perspective on Issues of Growth and Measurement, written for the Center that provides a much more detailed, but accessible, review of the issues we have tried to touch on above (Pellegrino, 2009).

\footnotetext{
${ }^{2}$ While the use of the term "psychometric" invokes a measurement metaphor that, as we suggest, may not be fully appropriate given newer conceptions of the underlying cognitive and social structures of students' performance, modern psychometric approaches are capable of modeling and supporting interpretations of complex mixtures of cognitive structures and traits, some of them discrete and some continuous, if that seems necessary to do justice to the complexity of human learning and performance. For instance, they might be able to provide independent estimates of the contributions of instruction and aptitude to students' performance-factors that have forever been confounded in conventional approaches to testing. These modelsones based on such things as Structured Item Response Theory (SIRT) or Bayesian Inference Networks (Rupp \& Mislevy, 2007; Mislevy, 2008) - are complicated and unfamiliar to policymakers, and they would represent serious overkill if they were applied to day-to-day classroom assessment. But used for large scale assessment and accountability purposes, they hold out the possibility of designing such assessments so that they can report at a larger grain size in ways that are consistent with the smaller-grain progression-based categories teachers should be using in their day to day work. As an example of what might be possible, the Rupp \& Mislevy 2007 paper reports the application of SIRT approaches in the recent development of large-scale standards-based assessments in Germany.
} 


\section{Conclusions and Recommendations}

We draw four conclusions and recommendations from the deliberations of our two working groups and our reflections on them in writing this brief:

- Progressions can provide a coherent grounding for designing standards, curricula, and formative and summative assessment in ways that are consistent with each other and supportive of instruction that is responsive to the needs of all students.

- The development of progressions grounded in direct evidence of the ways students' learning proceeds in response to well designed instruction is at early stages and covers only a small portion of the goals of K-12 schooling. Expanding that evidence and coverage should be a high priority focus of research and development funding, and within that focus particular priority should be given to the areas in which we know students have the most difficulty.

- However, we do not need to wait for such investments to pay off before we make attempts to use the best of what we know now to revise current curricula, standards, and assessments; we can begin now to make them coherent with each other, sensible about how learning is likely to develop over time, and disciplined by close attention to how students are actually understanding the material and growing in that understanding and skill over the school years.

- If curricula and assessments developed in this way are subjected to close empirical study as they are implemented in schools, the resulting evidence of student learning should support the further identification and refinement of learning progressions that could inform future designs in a virtuous cycle of continuous instructional improvement.

\section{References Cited}

Alonzo, A.C., Neidorf, T., \& Anderson, C.W. (forthcoming). Using learning progressions to inform large-scale assessment. In A. C. Alonzo and A.W. Gotwals, A. W. (Eds.), Learning progressions in science. Rotterdam, The Netherlands: Sense Partners.

Barrett, J.E., \& Battista, M.T. (in press 2011). A case study of different learning trajectories for length measurement. In J. Cenfrey, A. Maloney, and K. Nguyen (Eds.), Learning over time: Learning trajectories in mathematics education. Raleigh, North Carolina: Information Age Publishing.
Barrett, J. E., Clements, D. H., Cullen, C, McCool, J., Witkowski, C., \& Klanderman, D. (2009). Children's abstraction of iterative units to measure linear space: A trajectory. Paper presented at the Annual Meeting of the American Educational Research Association. San Diego, CA.

Case, R., Okamoto, Y., Griffin, S., McKeough, A., Bleiker, C., Henderson, B., et al. (1996). The role of central conceptual structures in the development of children's thought. Monographs of the Society for Research in Child Development, 61(1-2), pp. i+iii-vi+1-295.

CCSSO/NGA. (2010). Common core state standards for mathematics. Washington, DC: Council of Chief State School Officers and the National Governors Association Center for Best Practices. Retrieved from http:// www.corestandards.org/assets /CCSSI_Math\%20Standards.pdf

Center for K-12 Assessment \& Performance Management, Educational Testing Service (n.d.) http://www.k12center.org/index.html

Clements, D. H., \& Sarama, J. (2009). Learning and teaching early math: The learning trajectories approach. New York: Routledge.

Confrey, J., Maloney, A., \& Nguyen, K. (2011). Learning over time: Learning trajectories in mathematics education. Charlotte, NC: Information Age Publishers.

Confrey, J., Maloney, A., Nguyen, K., Mojica, G., \& Myers, M. (2009). Equipartitioning/splitting as a foundation of rational number reasoning using learning trajectories. Paper presented at The 33rd Conference of the International Group for the Psychology of Mathematics Education, Thessaloniki, Greece.

Corcoran, T., Mosher, F. A., \& Rogat, A. (2009). Learning Progressions in Science: An Evidence-based Approach to Reform (Research Report \#RR-63). Philadelphia: Consortium for Policy Research in Education.

Daro, P., Mosher, F. A., \& Corcoran, T. (2011). Learning trajectories in mathematics: A foundation for standards, curriculum, assessment, and instruction (Research Report \#68). Philadelphia: Consortium for Policy Research in Education.

Ginsburg, H. (1983). The development of mathematical thinking. New York: Academic Press.

Heritage, M. (2008) Learning progressions: Supporting instruction and formative assessment. http://www.ccsso.org/publications/details.cfm?PublicationsID $=366$.

Kennedy, C., \& Wilson, M. (2007). Using progress variables to interpret student achievement and progress (BEAR Technical Report No. 2006-12-01). University of California, Berkeley.

Kuhn, D. (2005). Education for thinking. Harvard University Press. 
Lehrer, R. \& Schauble, L. (2000). Modeling in mathematics and science. In R. Glaser (Ed.), Advances in instructional psychology: Education design and cognitive science (vol. 5, pp. 101-169). Mahway, NJ: Lawrence Erlbaum Associates.

Masters, G. N., Adams, R. A., \& Wilson, M. (1990). Charting student progress. In T. Husen \& T. N. Postlethwaite (Eds.), International encyclopedia of education: Research and studies. Supplementary volume 2 (pp. 628-634). Oxford, England: Pergamon Press.

Mislevy, R.J. (2008). How cognitive science challenges the educational measurement tradition. Measurement: Interdisciplinary Research and Perspectives, 6, 124. Available online at http://bearcenter.berkeley.edu/measurement/docs/CommentaryHaig_Mislevy.pdf

Mohan, L., Chen, J., \& Anderson, C.W. (2009). Developing a multi-year learning progression for carbon cycling in socio-ecological systems. Journal of Research in Science Teaching, 46 (6), 675-698.

National Research Council (2001). Knowing what students know: The science and design of educational assessment. Washington, DC: The National Academies Press.

National Research Council, Committee on Conceptual Framework for the New K-12 Science Education Standards. (2011, July). A framework for K-12 science education: Practices, crosscutting concepts, and core ideas. Washington, DC: The National Academies Press.

National Research Council (2007). Taking science to school: Learning and teaching science in grades $K-8$. Committee on Science Learning, Kindergarten through eighth grade. R.A. Duschl, H.A. Schweingruber, \& A.W. Shouse (Eds.). Washington DC: The National Academies Press.

Pellegrino, J. W. (2009). The design of an assessment system for the Race to the Top: A learning sciences perspective on issues of growth and measurement. Center for K-12 Assessment \& Performance Management, Educational Testing Service. http://www.k12center. org/rsc/pdf/PellegrinoPresenterSession1.pdf

Petit, M., Laird, R., \& Marsden, E. (2010). A focus on fractions; Bringing Research to the classroom. New York: Routledge.

Rupp, A. A., \& Mislevy, R. J. (2007). Cognitive foundations of structured item response theory models. In J. Leighton \& M. Gierl (Eds.), Cognitive diagnostic assessment in education: Theory and practice (pp. 205-241).

Sarama, J., \& Clements, D. H. (2009). Early childhood mathematics education research: Learning trajectories for young children. (pp.159-270). New York: Routledge.
Schwarz, C.V., Reiser, B.J., Davis, E.A., Kenyon, L., Achér, A., Fortus, D., Shwartz, Y., Hug, B., Krajcik, J. (2009). Developing a learning progression for scientific modeling: Making scientific modeling accessible and meaningful for learners. Journal of Research in Science Teaching, 46 (6), 632-654.

Smith, C., Wiser, M., Anderson, C.W, \& Krajcik, J. (2006). Implications of research on children's learning for standards and assessment: A proposed learning progression for matter and the atomic molecular theory. Measurement: Interdisciplinary Research and Perspectives, 14 (1\&2), 1-98.

Smith, C., Wiser, M., Anderson, C.W, Krajcik, J., \& Coppola, B. (2004, October). Implications for children's learning for assessment: Matter and atomic molecular theory. Paper Commissioned for the Committee on Test Design for K-12 Science Achievement. Center for Education, National Research Council.

Stevens, S.Y., Delgado, C., \& Krajcik, J.S. (2010). Developing a hypothetical multi-dimensional learning progression for the nature of matter. Journal of Research in Science Teaching, 47 (6), 687-715.

\section{About the Author}

\section{Frederic A. (Fritz) Mosher is Senior} Research Consultant to CPRE. Mosher is a cognitive/social psychologist and knowledgeable about the development and use of learning progressions. He has worked with CPRE on the CCII since its inception, helping to design the Center and taking a lead role in the Center's work on learning progressions.

Mosher also has extensive knowledge of, and connections with the philanthropic community, reform organizations, and federal agencies. He has been advisor to the Spencer Foundation, a RAND Corporation adjunct staff member, advisor to the Assistant Secretary for Research and Improvement in the U.S. Department of Education, and a consultant to Achieve, Inc. For thirty-six years he was a program specialist with varying responsibilities at Carnegie Corporation of New York. 


\section{GRE}

Graduate School of Education

University of Pennsylvania

3440 Market Street, Suite 560

Philadelphia, PA 19104-3325

\section{About the Consortium for Policy Research in Education (CPRE)}

Established in 1985, CPRE unites researchers from seven of the nation's leading research institutions in efforts to improve elementary and secondary education through practical research on policy, finance, school reform, and school governance. CPRE studies alternative approaches to education reform to determine how state and local policies can promote student learning. The Consortium's member institutions are the University of Pennsylvania, Teachers College-Columbia University, Harvard University, Stanford University, the University of Michigan, University of Wisconsin-Madison, and Northwestern University.

In March 2006, CPRE launched the Center on Continuous Instructional Improvement (CCII), a center engaged in research and development on tools, processes, and policies intended to promote the continuous improvement of instructional practice. CCII also aspires to be a forum for sharing, discussing, and strengthening the work of leading researchers, developers and practitioners, both in the United States and across the globe.

To learn more about CPRE and CCII, visit our web sites at www.cpre.org and www.ccii-cpre.org. **Sign up for CPRE's electronic newsletter, In-Sites (email insites@gse.upenn.edu), to receive updates on new CPRE publications, research project findings, and much more.

\section{Nondiscrimination Statement}

The University of Pennsylvania values diversity and seeks talented students, faculty, and staff from diverse backgrounds. The University of Pennsylvania does not discriminate on the basis of race, sex, sexual orientation, religion, color, national, or ethnic origin, age, disability, or status as a Vietnam Era Veteran or disabled veteran in the administration of educational policies, programs or activities; admissions policies, scholarships or loan awards; athletic, or University administered programs or employment.

Questions or complaints regarding this policy should be directed to Executive Director, Office of Affirmative Action, 1133 Blockley Hall, Philadelphia, PA 19104-6021 or (215) 898-6993 (Voice) or (215) 898-7803 (TDD). 